\title{
EGF and EGFR genetic polymorphisms predict prognosis in locally advanced pharyngolaryngeal squamous cell carcinoma patients receiving postoperative concurrent chemoradiotherapy
}

\author{
This article was published in the following Dove Press journal: \\ OncoTargets and Therapy \\ 28 November 2014 \\ Number of times this article has been viewed
}

\author{
Nai-Wen Su' \\ Yi-Shing Leu ${ }^{2}$ \\ Jehn-Chuan Lee ${ }^{2}$ \\ Chung-Ji Liu ${ }^{3}$ \\ Chieh-Yuan Cheng ${ }^{3}$ \\ Jiun-Sheng $\operatorname{Lin}^{3}$ \\ Yu-Jen Chen ${ }^{4}$ \\ Chi-Kuan Chen ${ }^{5}$ \\ I-Chih Fang ${ }^{6}$ \\ Ruey-Kuen Hsieh' \\ Yi-Fang Chang ${ }^{1,6}$ \\ 'Division of Medical Oncology \\ and Hematology, Department of \\ Internal Medicine, ${ }^{2}$ Department of \\ Otorhinolaryngology, ${ }^{3}$ Department \\ of Oral and Maxillofacial Surgery, \\ ${ }^{4}$ Department of Radiation Oncology, \\ ${ }^{5}$ Department of Pathology, ${ }^{6}$ Good \\ Clinical Research Center, Department \\ of Medical Research, Mackay Memorial \\ Hospital, Taipei, Taiwan
}

\begin{abstract}
Background: Epidermal growth factor (EGF) and its receptor (EGFR) are part of an important signaling pathway that is involved in the pathogenesis of squamous cell carcinoma of the head and neck (SCCHN). We hypothesized that EGF/EGFR genetic polymorphisms might have a prognostic impact on disease-free survival and overall survival (OS) in locally advanced SCCHN.
\end{abstract}

Materials and methods: The patient group included a consecutive cohort of 180 patients with locally advanced SCCHN who underwent postoperative concurrent chemoradiotherapy between 2002 and 2010. DNA from formalin-fixed, paraffin-embedded tumor tissues was genotyped for the single nucleotide polymorphism (SNP) of EGF A61G A $>$ G, EGFR R521K G $>$ A and G-216T. The log-rank test was applied to evaluate the impact of SNPs on the outcomes. Survival was estimated using the Kaplan-Meier statistical method.

Results: We demonstrated that EGF/EGFR SNPs might predict prognosis in patients with primary pharyngolaryngeal tumors, but not in those with oral cavity tumors. In pharyngolaryngeal tumor subgroup, EGF61 G/G genotype led to worse 5 year OS rate when compared to G/A or $\mathrm{A} / \mathrm{A}$ genotypes $(13.3 \%$ versus $34.3 \%$ versus $50.0 \%, P=0.017)$. The 5 year OS of patients with EGFR R521K G/G (11.1\%) and G/A (15.9\%) were lower than the A/A (62.5\%) genotype $(P=0.054)$. Patients carrying one or two unfavorable alleles had worse 5 year OS than those without unfavorable allele (not available versus $20 \%$ versus $71.4 \%, P=0.002$ ). Multivariate analysis revealed that the highest risk of death was associated with the coexistence of two unfavorable genotypes (hazard ratio 25.7, 95\% confidence interval $=3.4-193.4 ; P=0.002$ ).

Conclusion: In this study, we were able to demonstrate that the EGF A61G and EGFR R521K genetic polymorphisms might be important prognostic factors in patients with locally advanced primary pharyngolaryngeal squamous cell carcinoma who underwent postoperative concurrent chemoradiotherapy.

Keywords: polymorphisms, EGF A61G, EGFR R521K, head and neck cancer, biomarker

\section{Background}

Nai-Wen Su

Division of Medical Oncology and Hematology, Department of Internal Medicine, Mackay Memorial Hospital, B2 floor oncology/hematology office, No 92, Sec 2, Zhong-Shan N Rd, Taipei 10449, Taiwan

Tel +886225433535 ext 3454

Fax +886225 II 8424

Email changyifang@gmail.com;

medicine_su@hotmail.com
Squamous cell carcinoma of the head and neck (SCCHN) is the sixth most common cancer worldwide, and over $60 \%$ of the patients show locally advanced disease at presentation. ${ }^{1}$ Curative surgery followed by adjuvant concurrent chemoradiotherapy (CCRT), guided by the grading of pathologic risk features, is the standard of care for most tumors originating in the oral cavity and for part of the pharyngolaryngeal tumors. ${ }^{2,3}$ Despite recent advances, over $50 \%$ of the patients experience treatment failures. ${ }^{4}$ Meanwhile, acute and late adverse effects are of great concern while we are 
attempting to use more aggressive therapeutic approaches in the pursuit of better outcomes. ${ }^{5}$ In practice, prognostic biomarkers would be of great help to make more targeted decisions with respect to treatment strategies.

The epidermal growth factor receptor (EGFR) is a cell surface receptor and belongs to the ErbB receptor family. The EGFR is widely expressed on the epithelial cells in various tissue. After ligand binding, the receptor forms homo- or heterodimers and activates receptor autophosphorylation which triggers a series of intracellular signaling. Epidermal growth factor (EGF) is one of the ligands binding to ErbB receptors. In cancer cells, the EGFR signaling pathway is often deregulated which promotes their proliferation, resistance to apoptosis, ability to metastasize, and angiogenesis. ${ }^{6-9}$ The EGFR pathway activation is associated with the development of the SCCHN malignant phenotype and tumor growth. ${ }^{10,11}$ Overexpression of EGFR and of its ligand are well documented in SCCHN. ${ }^{12,13}$ Furthermore, elevated EGFR expression predicts worse disease survival. ${ }^{14}$ EGF and EGFR genetic polymorphisms have been investigated for carcinogenesis and prognosis in several cancer types. ${ }^{15-18}$ An $\mathrm{A}>\mathrm{G}$ single nucleotide polymorphism (SNP) at position +61 of the EGF gene was shown to increase EGF production in cultured peripheral blood mononuclear cells. ${ }^{19}$ Patients with the EGF61 A>G (rs4444903) polymorphism have poor prognosis for different cancers. ${ }^{19,20}$ The EGFR R521K G $>$ A (rs2227983) SNP leads to an Arg (R) to Lys (K) substitution. This EGFR variant allele shows reduced ligand binding and decreased tyrosine kinase activity as compared to the wildtype G allele. ${ }^{21}$ The other EGFR SNP of interest is the -216 $\mathrm{G}>\mathrm{T}$ (rs712829) change in the sp1-binding site of the promoter region. In vitro, studies revealed that this replacement increases the promoter activity by $30 \% .^{22}$ Both these EGFR SNPs have prognostic implications mainly for colorectal cancer. ${ }^{23,24}$ Only one report examined EGFR polymorphisms and their prognostic association in SCCHN. ${ }^{25}$ In the current study, we investigated the three EGF/EGFR SNPs that are described above, and their correlation with prognosis, in a consecutive cohort of locally advanced SCCHN (LA-SCCHN) patients, all of whom received postoperative CCRT.

\section{Materials and methods Study cohort and treatment}

The study protocol was approved by the hospital's institutional review board. Retrospectively, we included patients with newly-diagnosed non-metastatic LA-SCCHN originating from the oral cavity, the oropharynx, the hypopharynx, or the larynx. All patients underwent curative surgery and received the planned radiotherapy $(\mathrm{RT})$ doses with concurrent chemotherapy in our institution. Patients who received cetuximab at any step as part of their treatment were excluded. Each tumor was staged according to the 2002 American Joint Committee on Cancer staging classification. In all surviving patients, follow-up was performed for at least 2 years.

Indications for postoperative CCRT were the presence of any major pathologic risk features, positive surgical margins or extracapsular nodal extensions, or at least two co-existing minor risk factors, including $\mathrm{T}$ classification (T3/T4), $\mathrm{N}$ classification (N2-3), close surgical margins (1-5 mm), perineural invasion, or lymphovascular invasion (LVI), and a poorly differentiated tumor. RT fractionation involved five consecutive daily fractions over the course of a week, with a 1.8-2.0 Gy fraction size. The RT techniques were 2D conventional RT and intensity-modulated radiotherapy. The planned RT dose to the primary tumor bed and the affected lymph node regions was 60-66 Gy. The concurrent chemotherapy regimen involved one of the following: single agent cisplatin (30 mg/m $\mathrm{m}^{2}$ weekly or $75 \mathrm{mg} / \mathrm{m}^{2}$ every 3 weeks), single agent tegafur-uracil (tegafur $300 \mathrm{mg} / \mathrm{m}^{2}$ daily), or the cisplatin/5-FU combination (cisplatin $15 \mathrm{mg} / \mathrm{m}^{2}$ and $5-\mathrm{FU}$ $750 \mathrm{mg} / \mathrm{m}^{2}$ daily in a 120 hour continuous infusion, on day 1 and day 29 during RT).

\section{DNA extraction and genotyping}

Genomic DNA was extracted from formalin-fixed paraffinembedded tissue blocks of the resected tumor, and EGF/ EGFR polymorphism genotyping was carried out. A total of 180 tumor samples were analyzed as each patient correlates to one tumor sample.

The primer and probe sequences used during this work were as follows: ${ }^{20,24,26}$

EGF61 $\mathrm{A}>\mathrm{G}$

forward primer: 5'-TGTCACTAAAGG AAAGGA-3'

reverse primer: 5'-TTCACAGAGTTTAACAGCCC-3

EGFR R521K G>A

forward primer: 5'-TGCTGTGA CCCACTCTGTCT-3'

reverse primer: 5'-CCAGAAGGTTGCACTTGTCC-3'

EGFR $-216 \mathrm{G}>\mathrm{T}$

forward primer: 5'-TGTCACTAAA GGAAAGGAGGT-3' reverse primer: 5-TTCACAGAGTTTAACAGCCC-3'

PCR reactions were carried out in $20 \mu \mathrm{L}$ reactions that contained 150 ng DNA template, $0.4 \mu \mathrm{M}$ of each primer, $10 \mu \mathrm{L} 2 \times$ GoTaq $^{\circledR}$ Green Master Mix, 5\% dimethyl sulfoxide, and nuclease-free water. PCR amplification involved an initial 
5 minute denaturation step at $95^{\circ} \mathrm{C}$, followed by 35 cycles of denaturation $\left(95^{\circ} \mathrm{C}\right.$ for 30 seconds), annealing $\left(57^{\circ} \mathrm{C}\right.$ for EGFR $\mathrm{R} 521 \mathrm{~K} \mathrm{G}>\mathrm{A}$ and EGF61 $\mathrm{A}>\mathrm{G}$ and $60^{\circ} \mathrm{C}$ for EGFR-216 $\mathrm{G}>\mathrm{T}$ for 60 seconds), and finally elongation $\left(72^{\circ} \mathrm{C}\right.$ for 7 minutes $)$. The resulting PCR products were analyzed on the ABI3730 Sequencer (Thermo Fisher Scientific, Waltham, MA, USA) which is a genetic analyzer for allele determination.

\section{Endpoints and statistical analysis}

The time to events was counted from the date of surgery to the event occurrence or to the last date of the study, December 31, 2012, whichever came first. Death from any cause was incorporated when calculating overall survival (OS). Disease recurrences, the presence of a second primary tumor, and death from any cause were events considered when evaluating disease-free survival (DFS). Patients were recorded as censor if no events occurred until the last follow-up or the end of study.

Survival rates were estimated using the Kaplan-Meier statistical method. The log-rank test was used to evaluate the possible impact of EGF and EGFR genetic polymorphisms, separately and in combination, on OS and DFS. Additional clinical factors were also included in the analysis. The multivariate Cox proportional hazards model was used to estimate the adjusted hazard ratio (HR) and the $95 \%$ confidence interval $(95 \% \mathrm{CI})$. All reported $P$-values were two-tailed and considered to be statistically significant for $P<0.05$. All statistical analyses were performed using SPSS version 12 (SPSS Inc., Chicago, IL, USA).

\section{Results \\ Patient characteristics and treatment outcomes}

From January 2002 to December 2010, a total of 180 LASCCHN patients were included in this study. The median age of all patients was 51 years (interquartile range $45-57$ years), and $176(97.8 \%)$ were male. Primary tumors were located to the oral cavity in $140(77.8 \%)$, the oropharynx in eight $(4.4 \%)$, the hypopharynx in $22(12.2 \%)$, and the larynx in ten $(5.5 \%)$ patients. The pathologic stage distribution was: stage III $15 \%$, stage IVa $75 \%$, and stage IVb $10 \%$. The median total RT dose was 6,480 cGy (interquartile range 6,300-6,600 cGy). Eighty-three (46.1\%) patients received 2D conventional RT and the others were treated by intensitymodulated radiotherapy. The median RT treatment duration was 7.3 weeks (interquartile range 6.7-8.1 weeks). One hundred $(55.6 \%)$ patients died and 112 patients had DFS events until the last follow-up date. After a median follow-up time of 32.0 months (interquartile range 15-68 months), the median OS and DFS were 56 and 37 months, respectively. There were 43 locoregional recurrences and 47 distant metastases. In the univariate analysis, $\mathrm{N}$ classification $\geq \mathrm{N} 2$, the presence of LVI, and extracapsular nodal extensions were poor prognosticators for 5 year OS and DFS. Detailed patient demographics and treatment outcomes are listed in Table 1.

\section{Genetic polymorphisms and outcome correlations}

The genotype frequencies for the three SNPs are presented in Table 2. No significant associations were detected between the three genotypes and OS or DFS when the entire study population was examined. When the primary location of the tumor was considered during the analysis, the EGF61 A $>\mathrm{G}$ and $\mathrm{R} 521 \mathrm{~K} \mathrm{G}>\mathrm{A}$ EGFR polymorphisms showed a significant prognostic impact in patients with primary pharyngolaryngeal tumors but not in those with oral cavity tumors (Table 2). In this subgroup, patients with the $\mathrm{A} / \mathrm{A}, \mathrm{A} / \mathrm{G}$, and $\mathrm{G} / \mathrm{G}$ EGF61 genotypes had 5 year OS rates of $50.0 \%, 34.3 \%$, and $13.3 \%$, respectively $(P=0.017$, Figure $1 \mathrm{~A})$. The EGF61 $\mathrm{G} / \mathrm{G}$ genotype also led to a lower 5 year DFS rate when compared to the G/A or the A/A genotypes (not available versus $29.8 \%$ and $50 \%, P=0.026$, Figure $1 \mathrm{~B}$ ). For the EGFR $\mathrm{R} 521 \mathrm{~K}$ genotype, the 5 year OS rates in patients carrying the three variants $(\mathrm{G} / \mathrm{G}, \mathrm{G} / \mathrm{A}$, and $\mathrm{A} / \mathrm{A})$ were $11.1 \%, 15.9 \%$, and $62.5 \%$, respectively ( $P=0.054$, Figure $1 C$ ). The 5 year DFS was significantly worse in patients with the $\mathrm{G} / \mathrm{G}(11.1 \%)$ and $\mathrm{G} / \mathrm{A}(0 \%)$ genotypes than in those with the $\mathrm{A} / \mathrm{A}(62.5 \%)$ genotype ( $P=0.038$, Figure $1 \mathrm{D})$. We did not observe any correlations between the EGFR -216 G $>$ T genotype and OS or DFS. From these results, we identified EGF61 G/G and EGFR R521K G/G and G/A as unfavorable genotypes for the primary pharyngolaryngeal tumors. Patients harboring one or two of these unfavorable alleles had a worse 5 year OS and DFS than those without these unfavorable alleles (not available versus $20 \%$ versus $71.4 \%, P=0.002$, Figure $1 \mathrm{E}$; not available versus $10.4 \%$ versus $71.4 \%, P=0.003$, Figure 1F).

We also investigated the correlation between the A61G EGF and the R521K EGFR genotypes and patient characteristics in the pharyngolaryngeal tumor subgroup. Patients with the $\mathrm{G} / \mathrm{G}$ EGF61 genotype had significantly lower T stage $(P=0.024)$ and more $\operatorname{LVI}(P=0.003)$ and perineural invasion $(P=0.027)$. There were no associations between the R521K EGFR genotypes and any patient characteristics (data not shown). 
Table I Patient characteristics and treatment outcome

\begin{tabular}{|c|c|c|c|c|c|}
\hline & \multirow{2}{*}{$\begin{array}{l}N=180 \\
n(\%)\end{array}$} & \multicolumn{2}{|c|}{ Overall survival } & \multicolumn{2}{|c|}{ Progression-free survival } \\
\hline & & 5 yr (\%) & $P$-value ${ }^{a}$ & 5 yr (\%) & $P$-value ${ }^{a}$ \\
\hline \multicolumn{6}{|l|}{ Age } \\
\hline$<50$ & $82(45.6)$ & 43.1 & 0.113 & 35.8 & 0.070 \\
\hline$\geq 50$ & $98(54.4)$ & 53.9 & & 49.3 & \\
\hline \multicolumn{6}{|l|}{ Sex } \\
\hline Female & $4(2.2)$ & 25.0 & 0.155 & 25.0 & 0.264 \\
\hline Male & $176(97.8)$ & 49.5 & & 43.6 & \\
\hline \multicolumn{6}{|l|}{ PT } \\
\hline $\mathrm{I}-2$ & $36(20.0)$ & 60.5 & 0.235 & 50.8 & 0.313 \\
\hline $3-4$ & I44 (80.0) & 46.1 & & 41.4 & \\
\hline \multicolumn{6}{|l|}{$\mathrm{pN}$} \\
\hline $0-1$ & $85(47.2)$ & 64.3 & $<0.001$ & 53.8 & 0.002 \\
\hline $2-3$ & $95(52.8)$ & 35.5 & & 34.1 & \\
\hline \multicolumn{6}{|l|}{ Surgical margin } \\
\hline Positive & $44(24.5)$ & 38.7 & 0.140 & 29.6 & 0.111 \\
\hline \multicolumn{6}{|l|}{ Negative } \\
\hline$\leq 0.5 \mathrm{~cm}$ & $101(56.1)$ & 55.4 & & 47.8 & \\
\hline$>0.5 \mathrm{~cm}$ & $35(19.4)$ & 44.0 & & 44.7 & \\
\hline \multicolumn{6}{|l|}{ Extracapsular extension } \\
\hline Negative & $152(84.4)$ & 51.8 & 0.017 & 44.9 & 0.056 \\
\hline Positive & $28(15.6)$ & 35.1 & & 35.4 & \\
\hline \multicolumn{6}{|l|}{ Tumor differentiation } \\
\hline Well-moderate & $163(90.6)$ & 48.6 & 0.648 & 43.1 & 0.540 \\
\hline Poor & $17(9.4)$ & 52.9 & & 44.1 & \\
\hline \multicolumn{6}{|c|}{ Lymphovascular invasion } \\
\hline No & $107(59.4)$ & 56.6 & 0.008 & 51.8 & 0.005 \\
\hline Yes & $73(40.6)$ & 37.7 & & 30.4 & \\
\hline \multicolumn{6}{|l|}{ Perineural invasion } \\
\hline No & $12 \mid(67.2)$ & 51.3 & 0.307 & 46.2 & 0.221 \\
\hline Yes & $59(32.8)$ & 44.4 & & 37.3 & \\
\hline \multicolumn{6}{|l|}{ RTT (weeks) } \\
\hline$\leq 7$ & $69(38.5)$ & 58.5 & & 54.2 & \\
\hline$>7$ & $110(61.5)$ & 42.5 & 0.163 & 37.3 & 0.126 \\
\hline \multicolumn{6}{|l|}{ Chemotherapy } \\
\hline Cisplatin/5-FU & |3| (72.8) & 48.8 & 0.936 & 43.7 & \\
\hline Cisplatin only & $42(23.3)$ & 49.2 & & 40.0 & 0.861 \\
\hline Tegafur-uracil only & $7(3.9)$ & 53.6 & & 53.6 & \\
\hline
\end{tabular}

Note: ${ }^{a} P$-values based on the log-rank test.

Abbreviations: T, pathologic tumor stage; N, pathologic nodal stage; RTT, radiation treatment time; yr, years.

\section{Multivariate analysis of treatment} outcome

Since the EGF A61G and EGFR R521K genotypes might be prognostic markers in pharyngolaryngeal tumors, we performed univariate analysis first in this subgroup of patients $(\mathrm{N}=40)$. We found that patients with higher pathologic $\mathrm{N}$ stage, poor tumor differentiation, LVI and one or two unfavorable genotypes correlated with poor prognosis by univariate analysis. We included the above factors into multivariate analysis and significant HR for death was observed in patients $<50$ years old (adjusted $\mathrm{HR}=2.6,95 \% \mathrm{CI}=1.1-6.1$; $P=0.03$ ), poor tumor differentiation (adjusted HR $=9.9$, 95\% CI $=1.9-50.6 ; P=0.006$ ), and one or two unfavorable genotypes (adjusted $\mathrm{HR}=5.3,95 \% \mathrm{CI}=1.1-25.3 ; P=0.037$, and adjusted $\mathrm{HR}=25.7,95 \% \mathrm{CI}=3.4-193.4 ; P=0.002$, respectively) (Table 3). As for DFS, patients with poor tumor differentiation and the coexistence of two unfavorable genotypes had significantly worse outcomes (Table 3 ).

\section{Discussion}

In this study, we showed that EGF and EGFR genetic polymorphisms correlate with prognosis in patients with primary pharyngolaryngeal squamous cell carcinoma. We revealed that the EGF61 G/G and the EGFR R521K G/G and G/A genotypes are unfavorable genotypes, and the presence of one or two unfavorable alleles resulted in a worse outcome in this patient subgroup. The genotype frequencies were comparable whether they were examined overall in the 


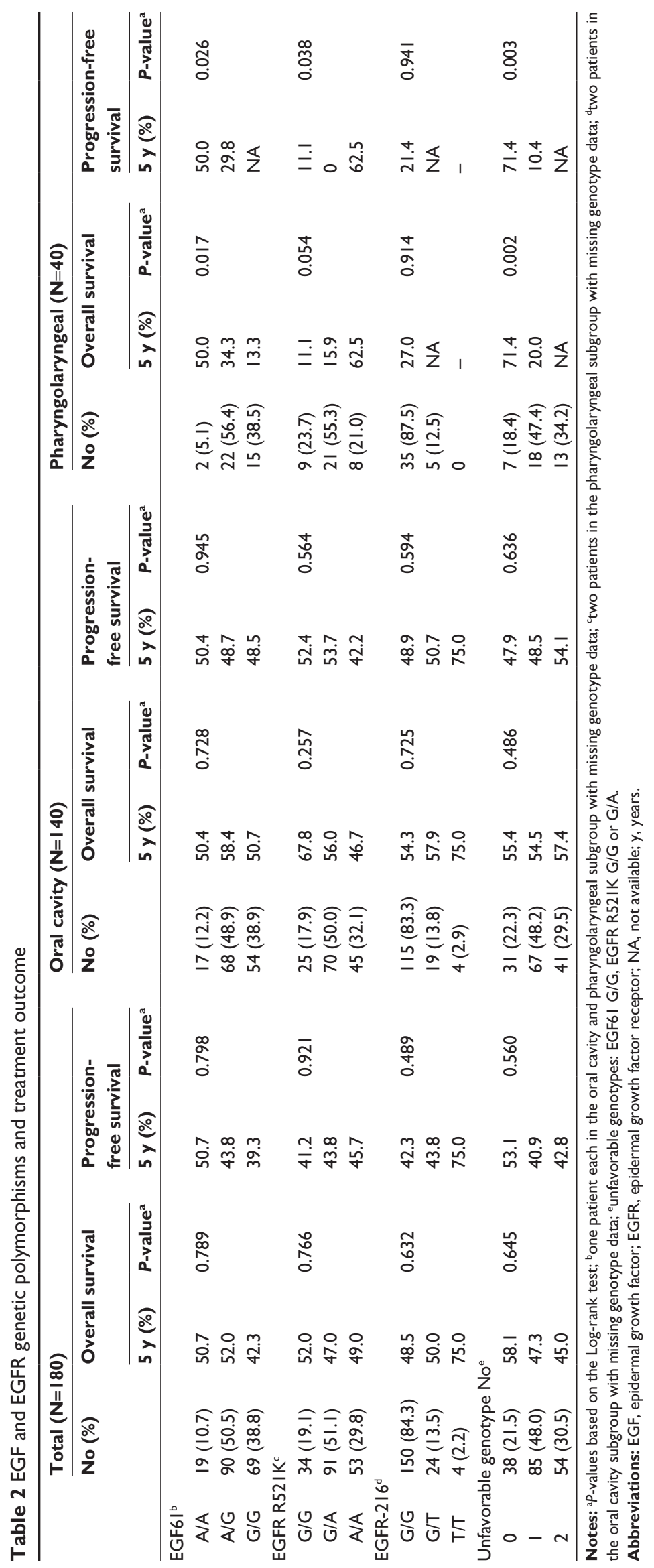


A

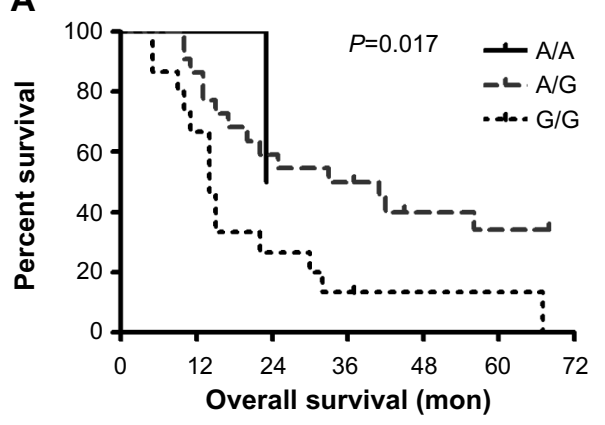

C

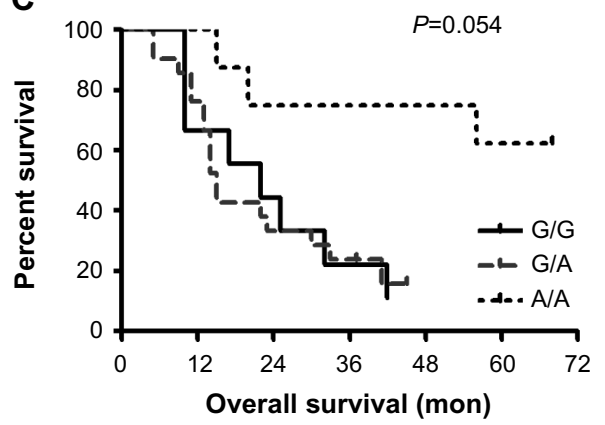

E

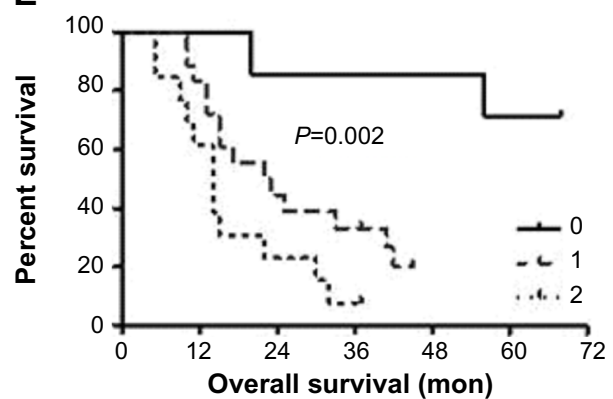

B

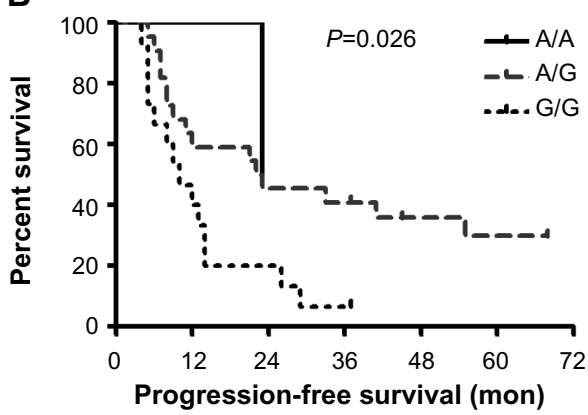

D

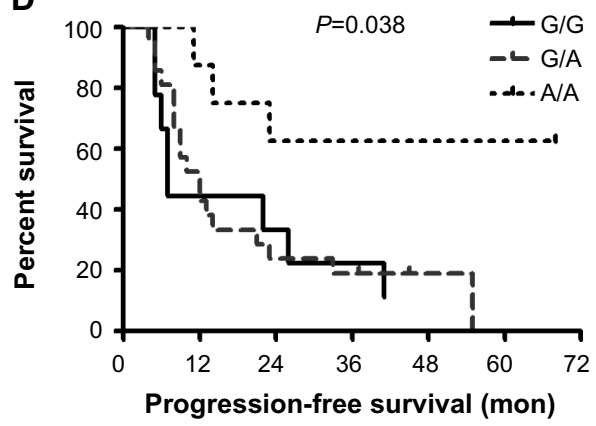

F

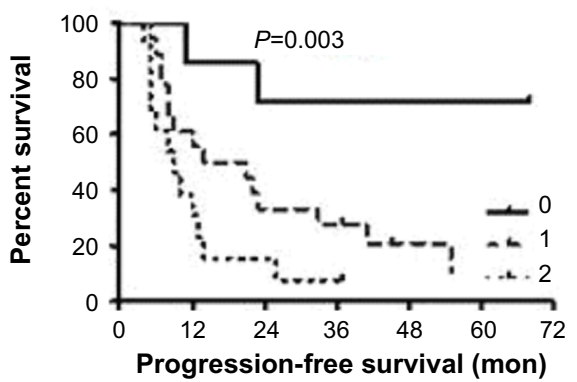

Figure I Kaplan-Meier curve showing overall survival and disease-free survival.

Notes: Patients with primary pharyngolaryngeal tumors having the EGF6I A $>$ G (A and B) and EGFR R52IK G $>$ A (C and D) genotypes, as well as the number of co-existing unfavorable genotypes (E and F). Unfavorable genotypes were defined as EGF6I G/G and EGFR R52IK G/G or G/A.

Abbreviations: EGF, epidermal growth factor; EGFR, epidermal growth factor receptor; mon, months.

entire study cohort or categorized according to the primary tumor location. The fact that the prognostic effect of the EGF/EGFR SNPs was restricted to the primary pharyngolaryngeal tumor subgroup was unexpected, and further studies are needed to confirm this finding. The genotype frequencies in our cohort were similar to the ones found in other reports of Asian populations, though different cancer types were looked at. ${ }^{24,27}$ The major limitation of the current study is its retrospective nature and the relatively small sample size. Our findings focused on an Asian population of individuals who received postoperative CCRT. These results should be tested in larger case series and in other ethnic groups.

The poor prognostic genotypes unveiled in this study also predict inferior outcomes for other cancer types. ${ }^{22,24,28}$ The only study investigating EGFR polymorphisms in SCCHN was reported by Bandres et al. ${ }^{25}$ They found that the R $521 \mathrm{~K}$ $\mathrm{R} / \mathrm{R}$ or $\mathrm{R} / \mathrm{K}$ EGFR genotypes, in combination with short $(\mathrm{CA})$ repeats $(<17)$, predicted survival. However, the study included stage II and metastatic patients who underwent surgery or received CCRT as the primary therapy, and this might have confounded their analysis.

With the advent of EGFR targeted therapy, we could now inhibit this important signaling pathway in SCCHN. One of the targeted agents, cetuximab, was shown to be effective and tolerated when administered concurrently with radiotherapy ${ }^{29}$ or in combination with platinum-based chemotherapy. ${ }^{30}$ Unlike metastatic colorectal cancer in which the $\mathrm{K}-\mathrm{RAS}$ mutation is an established negative predictor of the response to cetuximab, ${ }^{31}$ no biomarkers have been validated 
Table 3 Cox proportional hazards regression for patients with pharyngolaryngeal tumors

\begin{tabular}{|c|c|c|c|c|c|c|}
\hline & \multicolumn{3}{|c|}{ Overall survival } & \multicolumn{3}{|c|}{ Progression-free survival } \\
\hline & Adj HR & $95 \% \mathrm{Cl}$ & $P^{a}$ & Adj HR & $95 \% \mathrm{Cl}$ & $P^{a}$ \\
\hline \multicolumn{7}{|l|}{ Age (years) } \\
\hline$\geq 50$ & 1.0 & & & 1.0 & & \\
\hline$<50$ & 2.6 & $(1.1-6.1)$ & 0.030 & 1.6 & $(0.7-3.7)$ & 0.278 \\
\hline \multicolumn{7}{|l|}{$\mathrm{pN}$} \\
\hline $0-1$ & 1.0 & & & 1.0 & & \\
\hline $2-3$ & 2.5 & $(0.8-7.4)$ & 0.106 & 1.8 & $(0.7-5.0)$ & 0.239 \\
\hline \multicolumn{7}{|c|}{ Tumor differentiation } \\
\hline Well-moderate & 1.0 & & & 1.0 & & \\
\hline Poor & 9.9 & $(1.9-50.6)$ & 0.006 & 10.6 & $(1.9-58.7)$ & 0.007 \\
\hline \multicolumn{7}{|c|}{ Lymphovascular invasion } \\
\hline No & 1.0 & & & 1.0 & & \\
\hline Yes & 0.4 & $(0.1-1.4)$ & 0.139 & 0.8 & $(0.3-2.8)$ & 0.780 \\
\hline \multicolumn{7}{|c|}{ Unfavorable genotype $\mathrm{No}^{\mathrm{b}}$} \\
\hline 0 & 1.0 & & & 1.0 & & \\
\hline I & 5.3 & $(I . I-25.3)$ & 0.037 & 3.9 & $(0.9-16.9)$ & 0.065 \\
\hline $2-$ & 25.7 & $(3.4-193.4)$ & 0.002 & 9.7 & $(1.8-52.9)$ & 0.009 \\
\hline
\end{tabular}

Notes: $P$-value in bold indicates a significant value $(P<0.05)$; ${ }^{P}$-values based on the Cox proportional hazards model; ${ }^{b}$ unfavorable genotype: EGF6I G/G, EGFR R52IK $\mathrm{G} / \mathrm{G}$ or $\mathrm{G} / \mathrm{A}$.

Abbreviations: Adj HR, adjusted hazard ratio; $\mathrm{Cl}$, confidence interval; pN, pathologic nodal stage.

for SCCHN. The copy number of the tumor EGFR gene had no predictive value. ${ }^{32}$ The 16 expression status and cetuximab-induced rash exceeding grade 2 were suggested as biomarkers that need further investigation. ${ }^{33,34}$ EGF/EGFR polymorphisms have been examined as predictive biomarkers to cetuximab treatment. Studies on metastatic colorectal cancer populations showed a trend towards better treatment outcomes in patients carrying the EGF61 G/G genotype, while the predictive value of the EGFR R521K genotype was more controversial. ${ }^{35-38} \mathrm{~A}$ similar analysis was reported in two studies of recurrent or metastatic SCCHN patients receiving cetuximab-based systemic therapies. ${ }^{39,40}$ Patients with the EGFR R521K G/G or EGF61 G/G genotypes had better outcomes in response to cetuximab. This implicates the likelihood that cetuximab might reverse the poor outcome associated with these unfavorable genotypes. However, these preliminary results were obtained in studies that enrolled limited patient numbers, and they need further verification.

In conclusion, this study demonstrates that the EGF61 G/G and the EGFR R521K G/G and G/A genotypes predict poor outcome in patients with locally advanced pharyngolaryngeal tumors receiving postoperative CCRT. The possible predictive role of EGF/EGFR polymorphisms in response to cetuximab treatment warrants further investigation in the same treatment setting.

\section{Acknowledgments}

This work was supported by the Department of Medical Research, Mackay Memorial Hospital, Project No
MMH-101-104. The authors thank An-chi Lo for her dedication and great help with the statistical analysis.

\section{Disclosure}

The authors have declared no conflicts of interest.

\section{References}

1. Argiris A, Karamouzis MV, Raben D, Ferris RL. Head and neck cancer. Lancet. 2008;371(9625):1698-1709.

2. Cooper JS, Pajak TF, Forastiere AA, et al. Postoperative concurrent radiotherapy and chemotherapy for high-risk squamous-cell carcinoma of the head and neck. N Engl J Med. 2004;350(19):1937-1944.

3. Bernier J, Domenge C, Ozsahin M et al. Postoperative irradiation with or without concomitant chemotherapy for locally advanced head and neck cancer. $N$ Engl J Med. 2004;350(19):1945-1952.

4. Psyrri A, Licitra L, Lacombe D, et al. Strategies to promote translational research within the European Organization for Research and Treatment of Cancer (EORTC) Head and Neck Cancer Group: a report from the Translational Research Subcommittee. Ann Oncol. 2010;21(10): 1952-1960.

5. Machtay M, Moughan J, Trotti A, et al. Factors associated with severe late toxicity after concurrent chemoradiation for locally advanced head and neck cancer: an RTOG analysis. J Clin Oncol. 2008;26(21): 3582-3589.

6. Ciardiello F, Tortoa G. EGFR antagonist in cancer treatment. $N$ Engl J Med. 2008;358(11):1160-1174.

7. Ciardiello F, Tortoa G. A novel approach in the treatment of cancer: targeting the epidermal growth factor receptor. Clin Cancer Res. 2001;7(10):2958-2970.

8. Gan HK, Burgess AW, Clayton AHA, Scott AM. Targeting of a conformationally exposed, tumor-specific epitope of EGFR as a strategy for cancer therapy. Cancer Res. 2012;72(12):2924-2930.

9. Hynes NE, Lane HA. ERBB receptors and cancer: the complexity of targeted inhibitors. Nat Rev Cancer. 2005;5(5):341-354.

10. Sheikh MS, Carrier F, Johnson AC, Ogdon SE, Fornace AJ Jr. Identification of an additional p53-responsive site in humen epidermal growth factor gene promotor. Oncogene. 1997;15(9):1095-1101. 
11. Psyrri A, Yu Z, Weingerger PM, et al. Quantitative determination of nuclear and cytoplasmic epidermal growth factor receptor expression in oral squamous cell carcinoma by using automated quantitative analysis. Clin Cancer Res. 2005;11(16):5856-5862.

12. Grandis JR, Tweardy DJ. Elevated levels of transforming growth factor alpha and epidermal growth factor receptor messenger RNA are early markers of carcinogenesis in head and neck cancer. Cancer Res. 1993;53(15):3579-3584.

13. Ongkeko WM, Altuna X, Weisman RA, Wang-Rodriguez J. Expression of protein tyrosine kinase in head and neck squamous cell carcinoma. Am J Clin Pathol. 2005;124(1):71-76.

14. Rubin Grandis J, Melhem MF, Gooding WE, et al. Levels of TGFalpha and EGFR protein in head and neck squamous cell carcinoma and patient survival. J Natl Cancer Inst. 1998;90(11):824-832.

15. Lanuti M, Liu G, Goodwin JM, et al. A functional epidermal growth factor (EGF) polymorphism, EGF serum level, and esophageal adenocarcinoma risk and outcome. Clin Cancer Res. 2008;14(10): 3216-3222.

16. Tanabe KK, Lemoine A, Finkelstein DM, et al. Epidermal growth factor gene functional polymorphism and the risk of hepatocellular carcinoma in patients with cirrhosis. JAMA. 2008;299(1):53-60.

17. Xu X, Xi L, Zeng J, Yao Q. A functional $+61 \mathrm{G} / \mathrm{A}$ polymorphism in epidermal growth factor is associatedwith glioma risk among Asians. PLoS One. 2012;7(7):e41470.

18. Leite MS, Giacomin LC, Piranda DN, et al. Epidermal growth factor receptor gene polymorphisms are associated with prognostic features of breast cancer. BMC Cancer. 2014;14:190.

19. Shahbazi M, Pravica V, Nasreen N, et al. Association between functional polymorphism in EGF gene and malignant melanoma. Lancet. 2001;359(9304):397-401.

20. Bhowmick DA, Zhuang Z, Wait SD, Weil RJ. A functional polymorphism in the EGF gene is found with increased frequency in glioblastoma multiforme patients and is associated with more aggressive disease. Cancer Res. 2004;64(4):1220-1223.

21. Moriai T, Kobrin MS, Hope C, Speck L, Korc M. A variant epidermal growth factor receptor exhibits altered type $\alpha$ transforming growth factor binding and transmembrane signaling. Pro Natl Acad Sci U S A. 1994;91(21):10217-10221.

22. Liu $\mathrm{W}$, Innocenti $\mathrm{F}, \mathrm{Wu} \mathrm{MH}$, et al. A functional common polymorphism in a sp1 recognition site of the epidermal growth factor receptor gene promoter. Cancer Res. 2005;65(1):46-53.

23. Gram Spindler KL, Nielsen JN, Lindebjerg J, Brandslund I, Jakobsen A. Prediction of response to chemoradiation in rectal cancer by a gene polymorphism in the epidermal growth factor receptor promoter region. Int J Radiat Oncol Biol Phys. 2006;66(2):500-504.

24. Wang WS, Chen PM, Chiou TJ, et al. Epidermal growth factor receptor R497K polymorphism is a favorable prognostic factor for patients with colorectal carcinoma. Clin Cancer Res. 2007;13(12):3597-3604.

25. Bandres E, Barricarte R, Cantero C, et al. Epidermal growth factor receptor (EGFR) polymorphisms and survival in head and neck cancer patients. Oral Oncol. 2007;43(7):713-719.

26. Liu G, Gurubhaqavatula S, Zhou W, et al. Epidermal growth factor polymorphisms and clinical outcomes in non-small-cell lung cancer patients treated with gefitinib. Pharmacogenomics J. 2008;8(2): $129-138$.
27. Han SW, Oh DY, Im SA, et al. Epidermal growth factor receptor intron 1 CA dinucleotide repeat polymorphism and survival of advanced gastric cancer patients treated with cetuximab plus modified FOLFOX6. Cancer Sci. 2010;101(3):793-799.

28. McCarron SL, Bateman AC, Theaker JM, Howell WM. EGF +61 gene polymorphism and susceptibility to and prognostic markers in cutaneous malignant melanoma. Int J Cancer. 2003;107(4):673-675.

29. Bonner JA, Harari PM, Giralt J, et al. Radiotherapy plus cetuximab for squamous-cell carcinoma of the head and neck. $N$ Engl $J$ Med. 2006;354(6):567-578.

30. Vermorken JB, Mesia R, Rivera F, et al. Platinum-based chemotherapy plus cetuximab in head and neck cancer. N Engl J Med. 2008;359(11): $1116-1127$

31. Karapetis CS, Khambata-Ford S, Jonker DJ, et al. K-ras mutations and benefit from cetuximab in advanced colorectal cancer. $N$ Engl J Med. 2008;359(17):1757-1765.

32. Licitra L, Mesia R, Rivera F, et al. Evaluation of EGFR gene copy number as a predictive biomarker for the efficacy of cetuximab in combination with chemotherapy in the first-line treatment of recurrent and/or metastatic squamous cell carcinoma of the head and neck: EXETREME study. Ann Oncol. 2011;22(5):1078-1087.

33. Vermorken JB, Stohlmacher-Williams J, Davidenko I, et al. Cisplatin and fluorouracil with or without panitumumab in patients with recurrent or metastatic squamous-cell carcinoma of the head and neck (SPECTRUM): an open-label phase 3 randomised trial. Lancet Oncol. 2013;14(8):697-710.

34. Bonner JA, Harari PM, Giralt J, et al. Radiotherapy plus cetuximab for locoregionally advanced head and neck cancer: 5-year survival data from a phase 3 randomised trial. And relation between cetuximabinduced rash and survival. Lancet Oncol. 2010;11(1):21-28.

35. Graziano F, Ruzzo A, Loupakis F, et al. Pharmacogenetic profiling for cetuximab plus irinotecan therapy in patients with refractory advanced colorectal cancer. J Clin Oncol. 2008;26(9):1427-1434.

36. Lurje G, Nagashima F, Zhang W, et al. Polymorphisms in cyclooxygenase-2 and epidermal growth factor receptor are associated with progression-free survival independent of K-ras in metastatic colorectal cancer patients treated with single-agent cetuximab. Clin Cancer Res. 2008;14(23):7884-7895.

37. Garm Spindler KL, Pallosgaard N, Rasmussen AA, et al. The importance of KRAS mutations and EGF61A $>$ G polymorphism to the effect of cetuximab and irinotecan in metastatic colorectal cancer. Ann Oncol. 2009;20(5):879-884.

38. Hsieh YY, Tzeng CH, Chen PM, Wang WS. Epidermal growth factor receptor R521K polymorphism shows favorable outcomes in KRAS wild-type colorectal cancer patients treated with cetuximab-based chemotherapy. Cancer Sci. 2012;103(4):791-796.

39. Klinghammer K, Knodler M, Schmittel A, Budach V, Keilholz U, Tinhofer I. Association of epidermal growth factor receptor polymorphism, skin toxicity, and outcome in patients with squamous cell carcinoma of the head and neck receiving cetuximan-docetaxel treatment. Clin Cancer Res. 2010;16(1):304-310.

40. Stoehlmacher-Williams J, Obermann L, Ehninger G, Goekkurt E. Polymorphisms of the epidermal growth factor receptor (EGFR) and survival in patients with advanced cancer of the head and neck (HNSCC). Anticancer Res. 2012;32(2):421-426.
OncoTargets and Therapy

\section{Publish your work in this journal}

OncoTargets and Therapy is an international, peer-reviewed, open access journal focusing on the pathological basis of all cancers, potential targets for therapy and treatment protocols employed to improve the management of cancer patients. The journal also focuses on the impact of management programs and new therapeutic agents and protocols on
Dovepress

patient perspectives such as quality of life, adherence and satisfaction The manuscript management system is completely online and includes a very quick and fair peer-review system, which is all easy to use. Visit http://www.dovepress.com/testimonials.php to read real quotes from published authors. 